\title{
RESISTÊNCIA MECÂNICA DO SOLO À PENETRAÇÃO INFLUENCIADA PELO TRÁFEGO DE UMA COLHEDORA EM DOIS SISTEMAS DE MANEJO DO SOLO
}

\author{
SOIL STRENGTH AS AFFECTED BY COMBINE WHEEL TRAFFIC AND TWO SOIL TILLAGE \\ SYSTEMS
}

\author{
Vanderlei Rodrigues da Silva ${ }^{1}$, Dalvan José Reinert ${ }^{2}$, José Miguel Reichert ${ }^{2}$
}

RESUMO

A resistência mecânica do solo à penetração pode limitar o crescimento do sistema radicular e a produtividade das plantas. O estudo objetivou avaliar a resistência mecânica do solo à penetração nas zonas de tráfego e entre tráfego de uma colhedora de grãos, em dois sistemas de manejo do solo e duas condiçôes de umidade do solo. Os tratamentos foram: plantio direto, não trafegado pelas rodas da colhedora e no rastro do pneu dianteiro da colhedora; na área com preparo do solo, não trafegado pelas rodas da colhedora e no rastro do pneu dianteiro da colhedora. Determinaram-se a resistência mecânica do solo à penetração com um penetrógrafo, realizando leituras eletrônicas de resistência a cada $0,15 \mathrm{~cm}$ de profundidade, e a umidade do solo, até uma profundidade de $40 \mathrm{~cm}$, em duas condições de umidade do solo (seco e úmido), num Latossolo VermelhoEscuro, argiloso. Nesses mesmos locais, foram coletadas amostras para determinação da umidade do solo. O peso distribuído no eixo dianteiro da colhedora foi de 5,0Mg, sendo a área de contato com o solo igual a $0,283 \mathrm{~m}^{2}$, exercendo uma pressão de contato com o solo de 0,0884MPa. Com maiores conteúdos de água no solo, a resistência mecânica à penetração foi baixa (menor que $2 \mathrm{MPa}$ ) entre os diferentes tratamentos, não limitando o crescimento radicular. Porém, na segunda avaliação, quando o solo estava mais seco, verificou-se que o tráfego da colhedora causou compactação na camada de 5 a $17 \mathrm{~cm}$. O conteúdo de água do solo influenciou os valores absolutos de resistência mecânica à penetração. Valores de resistência mecânica à penetração considerados como críticos ao desenvolvimento das plantas (maiores que 2,0MPa) foram observados, principalmente, para o sistema de plantio direto. Os maiores valores de resistência à penetração foram encontrados no sistema de plantio direto que apresentou maior estado de compactação na camada de 7,5 a $17,0 \mathrm{~cm}$. O sistema de plantio direto possui um estado de compactação mais elevado, causado pelo acúmulo de pressões mecânicas a que o solo é submetido anualmente. Entretanto, a produtividade da cultura da soja não diferiu entre os sistemas de manejo do solo, permanecendo em torno de $3,15 \mathrm{Mg} \mathrm{ha}^{-1}$.
Palavras-chave: compactação, plantio direto, umidade, produtividade da soja

\section{SUMMARY}

The increase of soil mechanical resistance may limit plant growth and productivity. The objective of this paper was to evaluate the effects of wheel traffic caused by a grain harvester (combine) on penetration resistance for two soil tillage systems. The treatments were: no tillage, no wheel traffic and wheel traffic by a soybean harvester; tillage, no wheel traffic and at wheel traffic by a soybean harvester. Soil penetration resistance with a cone penetrograph with electronic readings for each $0.15 \mathrm{~cm}$ depth, and soil moisture were determined down to a depth of the $40 \mathrm{~cm}$, at two soil conditions (dry and wet), on a clayey Haplortox $(L E)$. The combine front-axle load was 5.0Mg and the wheel contact area was $0.283 \mathrm{~m}^{2}$, yielding a ground pressure of $0.0884 M P a$. For high soil moisture the soil resistance difference between treatments was low (smaller than 2,OMPa), not limiting to root growth. However, for the second evaluation, about 30 days after the first, when the soil was drier, soil compaction in the layer from 5 to $17 \mathrm{~cm}$ caused by wheel traffic was observed. Soil water content influenced the values of soil resistance. Critical values, considered as penetration resistance greater than $2 \mathrm{MPa}$, were mainly observed for the no tillage system, specially for the 7.5 to $17.0 \mathrm{~cm}$ layer. The no tillage system had a greater state of compaction than the tilled soil, because of yearly load accumulations. Soybean yield was not different between the tillage systems, with an average of $3.15 \mathrm{Mg} \mathrm{ha}^{-1}$ yield.

Key words: soil compaction, no tillage, penetration resistance.

\section{INTRODUÇÃO}

A compactação do solo é um processo de densificação na qual há um aumento da resistência

\footnotetext{
${ }^{1}$ Engenheiro Agônomo, Mestre, doutorando do Programa de Pós-graduação em Agronomia, Universidade Federal de Santa Maria (UFSM), 97105-900, Santa Maria, RS. E-mail: reichert@ ccr.ufsm.br. Autor para correspondência.

${ }^{2}$ Engenheiro Agrônomo, PhD., Professor Titular do Departamento de Solos, Centro de Ciências Rurais, UFSM. Bolsista do CNPq. Recebido para publicação em 04.08.99. Aprovado em 08.03.00
} 
do solo, redução da porosidade, continuidade de poros, da permeabilidade e da disponibilidade de nutrientes e água. Esse processo reduz o crescimento e o desenvolvimento radicular, aumenta as perdas de nitrogênio por denitrificação, o consumo de combustível para preparar solos compactados e aumenta a erosão do solo pela menor infiltração de água (SOANE \& OUWERKERK, 1994). Por diminuir a macroporosidade, a água que fica retida nos microporos está sob altas tensões, podendo estar indisponível para as plantas (KERTZMANN, 1996).

Os sistemas de manejo do solo têm grande influência nas características físicas do solo e estão relacionados com a compactação. O sistema de plantio direto é uma técnica eficiente no controle da erosão do solo, quando comparado com o sistema convencional (SEGANFREDO et al.,1997; BERTOL et al., 1997), porém alguns estudos indicam uma maior compactação no sistema de plantio direto (HAKANSSON \& MEDVEDEV, 1995; KERTZMANN，1996; KLEIN，1998), provocada pelo efeito cumulativo do tráfego de máquinas e acomodação natural das partículas sólidas. Porém, ALBUQUERQUE $\boldsymbol{e t}$ al. (1995) verificaram que não houve diferenças de densidade do solo, porosidade total e macro e microporosidade entre o sistema plantio direto e preparo convencional, num Latossolo Vermelho-Escuro. Da mesma forma, ANJOS et al. (1994), estudando sistemas de cultivos em quatro solos de Santa Catarina, verificaram um aumento de densidade do solo nos sistemas de manejo plantio direto, preparo reduzido e preparo convencional em relação à mata nativa, porém entre o sistema plantio direto e preparo convencional não verificaram diferenças de densidade do solo.

Devido à maior quantidade de matéria orgânica e atividade biológica na superfície, a estrutura de solos sob plantio direto pode ser mais favorável ao crescimento e desenvolvimento de plantas do que em solos cultivados convencionalmente, com igual ou ainda maior densidade do solo. Com a modernização da agricultura, o peso das máquinas e equipamentos e a intensidade de uso do solo têm aumentado, processo esse que não foi acompanhado por um aumento proporcional do tamanho e largura dos pneus, resultando em maior risco à compactação do solo. RUSANOV (1991) encontrou diferenças na produtividade de várias espécies em vários experimentos na Rússia, devido ao tipo de rodado que equipava os tratores. Segundo o autor, um trator equipado com rodado do tipo esteira, com massa de $6,5 \mathrm{Mg}$ e pressão de contato no solo de $0,05 \mathrm{MPa}$, causou redução de produtividade de diversas culturas em torno de $11 \%$, enquanto que os tratores equipados com pneus convencionais com uma massa de
$7,5 \mathrm{Mg}$ e pressão de contato de $0,08 \mathrm{MPa}$ e outro com massa de $11,8 \mathrm{Mg}$ com pressão de contato de $0,18 \mathrm{MPa}$, causaram uma redução de produtividade de diversas culturas em torno de 20 a $25 \%$.

Os pneus usualmente utilizados nos tratores e colhedoras comercializadas no Brasil possuem a parte lateral do pneu (carcaça) rígida, sendo chamados de pneus de banda diagonal. Essa rigidez impede que o pneu se molde no solo de acordo com as irregularidades do terreno, e, por isso, a sua área de contato fica reduzida, aumentando a pressão na superfície do solo. FLOWERS \& LAL (1998) relatam que a principal causa da compactação em solos agrícolas é o tráfego de máquinas em operações de preparo do solo, semeadura, tratos culturais e colheita. HORN et al. (1995) acrescentam que não somente a pressão estática (tensão normal) causa compactação, mas também forças dinâmicas causadas pela vibração do trator arrastando implementos e pelo patinamento.

A compactação subsuperficial é função da carga total por eixo e a compactação superficial é função da pressão de inflação dos pneus (SALIRE $\boldsymbol{e} t$ al., 1994; HAKANSSON \& VOORHEES, 1997). Segundo VOORHEES $\boldsymbol{e}$ t al. (1986) e VOORHEES et al. (1978), as máquinas agrícolas com carga por eixo acima de $4,5 \mathrm{Mg}$ causaram aumento de resistência à penetração e densidade do solo a profundidades maiores que $30 \mathrm{~cm}$, sendo, então, necessárias máquinas de grande potência e uma maior demanda de combustível para cultivar esses solos compactados.

O conceito de um valor crítico de densidade do solo no qual o crescimento de raízes é prejudicado tem sido suportado por THOMPSON $\boldsymbol{e t}$ al . (1987) e HAKANSSON \& VOORHEES (1997) como o melhor parâmetro físico que caracteriza o crescimento de raízes em solos compactados. Outros pesquisadores sugerem que a densidade do solo não é o fator mais limitante ao crescimento radicular, mas sim a resistência que o solo oferece ao crescimento das raízes, determinada por um penetrômetro (VOORHEES, 1983).

Embora o crescimento das raízes no solo não se dê em uma única direção, THOMPSON $\boldsymbol{e t}$ al. (1987) encontraram boa relação entre densidade radicular e a resistência à penetração medida pelo penetrômetro $\left(r^{2}=0,65\right)$. Para VEPRASKAS \& MINER (1986), valores de resistência à penetração de 2,8 a 3,2MPa retardam a elongação das raízes e com 4,0MPa não há crescimento de raízes. Considerando que uma redução de $40 \%$ do comprimento radicular é crítico à produtividade das plantas (PABIN et $\boldsymbol{a l} .$, 1998), CINTRA \& MIELNICZUK (1983) encontraram uma redução de 50\% no comprimento radicular de várias culturas, quando a 
resistência à penetração foi de $1,1 \mathrm{MPa}$, em um Latossolo Roxo, muito argiloso. Indicando que, nessa situação, a produtividade das plantas é reduzida com resistência mecânica à penetração de $1,1 \mathrm{MPa}$. Em camadas compactadas artificialmente de um solo Podzólico Vermelho-Escuro, o crescimento de raízes de trigo foi fortemente limitado quando a resistência do solo à penetração estava entre 3,5 e $5,5 \mathrm{MPa}$ (MEROTTO JR \& MUNDSTOCK, 1999). Como se pode verificar, existe uma grande amplitude de valores de resistência mecânica do solo à penetração considerados críticos ao desenvolvimento de raízes; então, o valor de $2,0 \mathrm{MPa}$ tem sido aceito como o limite crítico de resistência mecânica do solo à penetração (TAYLOR et al., 1966; NESMITH, 1987).

Esse estudo avaliou a resistência à penetração nas zonas de tráfego e entre tráfego da colhedora de soja em dois sistemas de manejo de solo e duas condições de umidade.

\section{MATERIAL E MÉTODOS}

O experimento foi realizado em lavoura, localizada no município de Ibirubá, região do Planalto Médio do Estado do RS. O solo no local é classificado como Latossolo Vermelho-Escuro (BRASIL, 1973), textura superficial argilosa, contendo na camada superficial $(0-12 \mathrm{~cm}) 480 \mathrm{~g} \mathrm{~kg}^{-1} \mathrm{de}$ argila, $323 \mathrm{~g} \mathrm{~kg}^{-1}$ de silte e $197 \mathrm{~g} \mathrm{~kg}^{-1}$ de areia, determinados pelo método da pipeta (Tabela 1). Na camada superficial $(0-10 \mathrm{~cm})$, foram determinados a densidade de partículas pelo método do balão volumétrico (EMBRAPA-SNLCS, 1997); limite de liquidez, limite de plasticidade e o índice de plasticidade pelo método Casagrande (SOWERS, 1965); a distribuição de agregados estáveis em água e expresso pelo diâmetro médio geométrico (KEMPER \& CHEPIL, 1965); e o conteúdo de carbono orgânico do solo pelo método Walkey \& Black (ALISSON, 1965).

A lavoura estava sendo manejada em sistema de plantio direto, por aproximadamente 10 anos, com culturas de soja (Glycine max L.) e milho

Tabela 1 - Valores de algumas características físicas do solo estudado e produtividade da soja.

\begin{tabular}{lccccccccc}
\hline Sistema & $\begin{array}{c}\text { DMG } \\
\text { mm }\end{array}$ & LL & LP & IP & $\begin{array}{c}\text { MO } \\
\text { argila }\end{array}$ & $\begin{array}{c}\text { silte } \\
\text { areia }\end{array}$ & $\begin{array}{c}\text { Prod. Soja } \\
\mathrm{Mg} \mathrm{ha}^{-1}\end{array}$ \\
\hline Plantio direto & 4,06 & 44 & 29 & 15 & 32,9 & 467 & 322 & 211 & 3,2 \\
Preparo reduzido & 4,47 & --- & --- & --- & 32,7 & --- & --- & --- & 3,1 \\
\hline
\end{tabular}

---= não determinado.
(Zea mays L.), no verão, e aveia (Avena strigosa Schieb) mais azevém (Lollium multiflorum Lam.), no inverno. Para este estudo, antes da semeadura da soja, parte da gleba recebeu preparo reduzido (uma escarificação e duas gradagens). A profundidade de trabalho do escarificador foi de aproximadamente $25 \mathrm{~cm}$, enquanto que as gradagens foram de 5 a $7 \mathrm{~cm}$. $\mathrm{Na}$ ocasião do preparo do solo, este se encontrava com umidade na parte inferior da faixa de friabilidade (determinação qualitativa). A semeadura da soja foi realizada em novembro de 1997, com a cultivar BR-16, e a colheita foi realizada no dia 09 de abril de 1998. Essas glebas estavam situadas lado a lado, em igual posição na paisagem.

As determinações de resistência do solo e a determinação da umidade gravimétrica foram realizadas nos seguintes locais: na área sob plantio direto, não trafegado pelas rodas da colhedora (PDNT) e no rastro do pneu dianteiro da colhedora (PDT); na área com preparo reduzido, não trafegado pelas rodas da colhedora (PRNT) e no rastro do pneu dianteiro da colhedora (PRT). O peso distribuído no eixo dianteiro da máquina em condições estáticas foi de $5,0 \mathrm{Mg}$ e a área de contato do pneu com o solo foi determinado medindo-se a largura e o maior comprimento do pneu que estava em contato com o solo. Multiplicando a largura $(0,45 \mathrm{~m})$ e o comprimento $(0,80 \mathrm{~m})$ pelo fator 0,7854 , tem-se a área de contato do pneu com o solo de $0,283 \mathrm{~m}^{2}$, que exerce uma pressão no solo de 0,0884MPa. Devido ao pequeno tamanho da lavoura amostrada, o peso adicional dos grãos no graneleiro não foi considerado.

A resistência do solo foi determinada usando-se um penetrógrafo (marca Rimic CP 10) de armazenamento eletrônico dos dados e leituras realizadas a cada $0,15 \mathrm{~cm}$ de profundidade, possuindo ponta cônica com ângulo de penetração de $30^{\circ}$ (ASAE, 1982). No dia da colheita da soja (09/04/1998), foram realizadas seis determinações de resistência do solo para cada tratamento. A umidade gravimétrica do solo foi determinada nos dois sistemas de manejo do solo e nas duas épocas de avaliação, somente na área sem tráfego e assumiu-se que, na área com tráfego, a umidade era semelhante (Tabela 2). Uma segunda avaliação de resistência do solo foi realizada aproximadamente um mês após a primeira (10/05/1998), quando o solo estava com menor teor de água, realizando-se nove repetições para os dados de resistência à penetração para cada tratamento.

A produtividade de grãos foi avaliada somente entre os 
Tabela 2 - Valores de umidade gravimétrica do solo $\left(\mathrm{kg} \mathrm{kg}^{-1}\right)$, ao longo do perfil, em dois sistemas de manejo do solo e em duas condições de umidade. Época 1, dia 09/04/1998 e época 2, dia 12/05/1998

\begin{tabular}{ccccc}
\hline \multirow{2}{*}{$\begin{array}{c}\text { Profundidade } \\
(\mathrm{cm})\end{array}$} & \multicolumn{2}{c}{ Plantio direto } & \multicolumn{2}{c}{ Preparo reduzido } \\
\cline { 2 - 5 } & Época 1 & Época 2 & Época 1 & Época 2 \\
& & & & \\
\hline & & & & \\
$0-5$ & 0,27 & 0,19 & 0,25 & 0,17 \\
$5-10$ & 0,25 & 0,22 & 0,25 & 0,24 \\
$10-15$ & 0,25 & 0,24 & 0,26 & 0,23 \\
$15-20$ & 0,25 & 0,26 & 0,28 & 0,25 \\
$20-40$ & 0,28 & 0,28 & 0,29 & 0,28 \\
& & & & \\
\hline
\end{tabular}

sistemas de manejo do solo, pois a resistência mecânica do solo à penetração foi determinada após a passagem da colhedora e a coleta de amostras para determinar a produtividade da soja foi realizada antes da passagem da colhedora. Coletaram-se plantas inteiras e maduras de soja de uma área de $4,05 \mathrm{~m}^{2}$, com três repetições, pesou-se a massa de grãos e corrigiu-se essa massa para umidade de $13 \%$.

O delineamento experimental utilizado foi inteiramente casualizado. Utilizou-se o teste DMS a 5\% de nível de significância para comparar médias de resistência à penetração do solo, para cada profundidade. As médias de produção de soja foram comparadas entre o sistema plantio direto e preparo reduzido.

\section{RESULTADOS E DISCUSSÃO}

$\mathrm{Na}$ primeira avaliação, com maior conteúdo de água no solo, os diferentes tratamentos apresentaram valores de resistência à penetração inferior a 2,0MPa (Figura 1), mas visualizou-se na camada de 0 a $5 \mathrm{~cm}$ uma maior resistência mecânica do solo à penetração na linha do tráfego, tanto no preparo reduzido como em sistema plantio direto. Evidenciando o efeito do tráfego da colhedora no aumento da compactação do solo, avaliada nesse trabalho, pelo aumento da resistência mecânica do solo à penetração. A maior resistência mecânica do solo à penetração deve-se ao não revolvimento do solo, que ano após ano vem acumulando pressões pelo tráfego de máquinas e, ainda, pela acomodação natural das partículas (CARVALHO JÚNIOR et $\boldsymbol{a l}$., 1998).

Nas profundidades de 6 até $10 \mathrm{~cm}$, as diferenças nos valores de resis- tência mecânica do solo à penetração não foram significativas entre os tratamentos, embora o sistema plantio direto (na linha de tráfego e entre as linhas de tráfego) tenha apresentado maior resistência à penetração. Na profundidade de 13,5 até $18 \mathrm{~cm}$, o tráfego da colhedora provocou maior resistência mecânica do solo à penetração, sendo que no preparo reduzido com tráfego, não houve diferença com o sistema plantio direto sem tráfego. Essa observação indica que apenas um evento de tráfego sobre o solo pode provocar um aumento de resistência à penetração para níveis semelhantes ao que estava antes da escarificação. No solo sob sistema plantio direto, o tráfego da máquina causou um leve aumento de resistência, pois, por possuir um estado de compactação mais elevado do que o solo que recebeu o preparo reduzido, pôde resistir à pressão exercida pelas rodas da colhedora, naquele teor de água no momento do tráfego sobre o solo.

A quantidade de matéria orgânica no sistema de plantio direto e no sistema com preparo do solo foi similar, em torno de $32,8 \mathrm{~g} \mathrm{~kg}^{-1}$ (Tabela 1). Da mesma forma, o diâmetro médio geométrico de agregados estáveis em água (DMG) apresentou valores muito próximos, em torno de 4,5mm (Tabela 1). A matéria orgânica do solo apresenta maior grau de elasticidade do que as partículas minerais do solo e proporciona uma maior agregação, pela formação e estabilização de agregados, agindo de maneira 
conjunta com a estrutura do solo no aumento da resistência mecânica do solo à compactação. Como ocorreu um aumento de resistência à penetração do solo após a passagem da colhedora, do tratamento sem tráfego para o tratamento com tráfego, no sistema de manejo de solo que recebeu preparo reduzido (Figura 2), esses valores de matéria orgânica e DMG não foram suficientes para conferir resistência mecânica ao solo para resistir ao tráfego da colhedora. Isso indica que, se o solo já estiver com um determinado estado inicial de compactação, ele será mais resistente a pressões externas, como verificado no sistema plantio direto.

$\mathrm{Na}$ camada de 1,5 a $6 \mathrm{~cm}$, os tratamentos plantio direto com e sem tráfego e no sistema com preparo reduzido na linha de tráfego da colhedora, os valores de resistência mecânica do solo à penetração foram duas vezes maiores que o sistema com preparo reduzido que não teve tráfego da colhedora. $\mathrm{Na}$ camada de 7,5 a $17,5 \mathrm{~cm}$, visualiza-se o efeito do tráfego da colhedora no sistema com preparo reduzido de solo. No sistema plantio direto, existe uma variabilidade nos valores de resistência mecânica do solo à penetração que proporcionou valores maiores de resistência à penetração para o sistema plantio direto sem tráfego do que para o sistema plantio direto que recebeu tráfego da colhedora.

A pressão de preconsolidação é um índice de resistência do solo à compactação (HOLTZ \&
KOLVACS, 1981). Quanto maiores os valores de pressão de preconsolidação, maiores pressões devem ser aplicadas sobre o solo para compactá-lo. Os valores de pressão de preconsolidação são influenciados pela matéria orgânica do solo, DMG, umidade e pelo estado de compactação que o solo se encontra. SILVA (1999) determinou que a pressão de preconsolidação nesse solo, na camada de zero a $2 \mathrm{~cm}$, foi de $0,14 \mathrm{MPa}$, para o sistema de plantio direto, e de $0,08 \mathrm{MPa}$, para o sistema com preparo do solo, na umidade semelhante à determinada na ocasião da passagem da máquina. Ou seja, na área que sofreu preparo do solo, a pressão exercida pela roda da colhedora foi maior que a capacidade de suporte do solo, deformando-o irreversivelmente. No sistema plantio direto, o acúmulo de pressões oriundas de cerca de 10 anos sem revolvimento do solo aumentou a pressão de preconsolidação, resultando em menor deformação do solo, quando esse foi submetido à pressão da roda da colhedora (Figura 2).

Com menor conteúdo de água no solo (Tabela 2 e Figura 2), ocorreram maiores diferenças de resistência mecânica do solo à penetração entre os sistemas de cultivo e entre os sistemas de tráfego (com e sem tráfego), até os $20 \mathrm{~cm}$ de profundidade. $\mathrm{O}$ preparo do solo com escarificador foi eficiente em reduzir a resistência mecânica do solo até a profundidade de $20 \mathrm{~cm}$; a partir dessa profundidade, existe um grande efeito da variabilidade da resistência mecânica do solo à penetração.

Em geral, os solos argilosos são mais suscetíveis à compactação pelo tráfego de máquinas do que os mais arenosos, devido à maior porosidade total e maior capacidade de armazenamento de água nos microporos daqueles (SILVA, 1999). Isso faz com que solo argiloso retenha mais umidade e por um período maior, necessitando maiores cuidados com a umidade do solo nas práticas de preparo do solo e tráfego de máquinas para reduzir os riscos de compactação. $\mathrm{O}$ limite de liquidez para esse solo foi de 44, o limite de plasticidade foi de 29 e o índice de plasticidade foi de 15 (Tabela 1). Portanto, no momento do tráfego da colhedora, o solo estava com umidade próxima ao limite de plasticidade, sendo, então, mais suscetível à compactação.

Comparando-se os sistemas de

Figura 2 - Resistência do solo (MPa) em profundidade, na época 2 (10/05/1998), entre as linhas e nas linhas de tráfego do pneu dianteiro de colhedora, em Latossolo Vermelho-Escuro submetido a dois sistemas de manejo do solo. Média de nove repetições. (PDNT =plantio direto não trafegado; PRNT $=$ preparo reduzido (escarificador mais duas gradagens) não trafegado; $\mathrm{PDT}=$ plantio direto trafegado; $\mathrm{PRT}=$ preparo reduzido (escarificador mais duas gradagens) trafegado). Barras horizontais comparam os valores de resistência à penetração, para cada profundidade, pelo teste DMS $(5 \%)$ cultivo onde não houve a passagem da roda da colhedora, percebe-se que, na camada de 7,5 a $17,5 \mathrm{~cm}$, ocorreram os maiores valores de resistência à penetração, cerca de 1,6 vezes maiores para o sistema de plantio direto em relação ao 
preparo reduzido, quando o solo estava mais úmido (Figura 1), e cerca de 3,0 vezes quando o solo estava mais seco (Figura 2). Segundo HAKANSSON \& MEDVEDEV (1995), esse estado diferenciado de compactação é o principal fator que limita a adoção do sistema de plantio direto.

Nas condições deste estudo, a cultura da soja teve um adequado desenvolvimento e a produtividade média foi $3,2 \mathrm{Mg} \mathrm{ha}^{-1}$ no sistema de plantio direto e $3,1 \mathrm{Mg} \mathrm{ha}^{-1}$ no sistema com preparo reduzido, não sendo diferentes estatisticamente (DMS, 5 $\%)$. Isso indica que, durante o ciclo da cultura da soja, períodos com maior conteúdo de água no solo ocasionaram menores valores de resistência mecânica do solo, possibilitando o desenvolvimento das raízes. LETEY (1985), TORMENA et al. (1998) e KLEIN (1998) e salientam que nem sempre o limitante da produtividade das culturas é a resistência mecânica do solo, mas sim, um conjunto de fatores, tais como a própria resistência do solo à penetração de raízes, o espaço aéreo destinado às trocas gasosas e a quantidade de água disponível para as plantas.

Nos dois manejos estudados e nas duas condições de umidade, o sistema de plantio direto apresentou maior resistência à penetração do que na área com revolvimento. Essa maior resistência do solo sob plantio direto fez com que ele resistisse à pressão causada pela roda da colhedora, enquanto que, no sistema com preparo reduzido, o solo não resistiu e houve um aumento de resistência que permaneceu durante o intervalo entre as avaliações.

\section{CONCLUSÕES}

As diferenças de resistência à penetração entre os sistemas de manejo do solo e onde foi trafegado com a colhedora são maiores quando o solo está mais seco. O efeito da diminuição da resistência do solo pelo preparo pode ser anulado por uma única passagem do pneu da colhedora. O sistema de plantio direto apresenta maiores valores de resistência à penetração e maior estado de compactação, especialmente na camada de 7,5 a $17,0 \mathrm{~cm}$. A maior resistência mecânica do solo à penetração não reduziu a produtividade da soja.

\section{AGRADECIMENTOS}

Os autores agradecem ao INIA-Tacuarembó, Uruguai, pelo empréstimo do penetrógrafo.

\section{REFERÊNCIAS BIBLIOGRÁFICAS}

ALBUQUERQUE, J.A., REINERT, D.J., FIORIN, J.E., et al. Rotação de culturas e sistemas de manejo do solo: efeito sobre a forma da estrutura do solo ao final de sete anos. Revis- ta Brasileira de Ciência do Solo, Campinas, v.19, p.115$119,1995$.

ALLISON, L.E. Organic carbon. In: BLACK, C.A. Methods of soil analysis. Part 2. Madison : ASA, 1965. p.1367-1378.

AMERICAM SOCIETY OF AGRICULTURAL ENGINEERS. Soil penetrometer. St. Joseph, MI : ASAE Standard: ASAE S313.1., 1982. p.246.

ANJOS, J.T., UBERTI, A.A.A., VIZZOTO, V.J., et al. Propriedades físicas em solos sob diferentes sistemas de uso e manejo. Revista Brasileira de Ciência do Solo, Campinas, v.18, p.139-145,1994.

BERTOL, I., COGO, N.P., LEVIEN, R. Erosão hídrica em diferentes preparos do solo logo após as colheitas de milho e trigo, na presença e na ausência dos resíduos culturais. Revista Brasileira de Ciência do Solo, Viçosa, v.21, p.409418, 1997.

BRASIL. Ministério da Agricultura. Levantamento de reconhecimento dos solos do Rio Grande do Sul. Recife, PE : Departamento Nacional de Pesquisa Agropecuária. Divisão de Pesquisa Pedológica. Ministério da Agricultura, 1973. 413p. (Boletim, 30)

CARVALHO JÚNIOR, I.A., FONTES, L.E.F., COSTA, L.M. Modificações causadas pelo uso e formação de camadas compactadas e, ou, adensadas em um Latossolo VermelhoEscuro textura média, na região do Cerrado. Revista Brasileira de Ciência do Solo, Viçosa, v.22, p.505-514, 1998.

CINTRA, F.L.D., MIELNICZUK, J. Potencial de algumas espécies vegetais para a recuperação de solos com propriedades físicas degradadas. Revista Brasileira de Ciência do Solo, Campinas, v.7, p.197-201, 1983.

EMPRESA BRASILEIRA DE PESQUISA AGROPECUÁRIA EMBRAPA. Centro Nacional de Pesquisa de Solos. Manual de métodos de análise do solos. 2 ed. Rio de Janeiro: EMBRAPA-CNPS, 1997. 212p.

FLOWERS, M.D., LAL, R. Axle load and tillage effects on soil physical properties and soybean grain yield on a mollic ochraqualf in northwest Ohio. Soil \& Tillage Research, Amsterdam, v.48, p.21-35, 1998.

HAKANSSON, I., MEDVEDEV, V.W. Protection of soils from mechanical overloading by establishing limits for stresses caused by heavy vehicles. Soil \& Tillage Research, Amsterdam, v.35, p.85-97, 1995.

HAKANSSON, I., VOORHEES, W.B. Soil compaction. In: LAL, R., BLUM, W.H., VALENTIN, C., et al. (eds.) Methods for assessment of soil degradation. Boca Raton: Lewis, 1997. p.167-179.

HOLTZ, R.D., KOLVACS, W.D. An introduction to geotechnical engineering. New Jersey : Prentice-Hall, 1981. $733 p$.

HORN, R., DOMZAL, H., SLOWINSKAJURKIEWICZ, A., et al. Soil compaction processes and their effects on the structure of arable soils and the environment. Soil \& Tillage Research, Amsterdam, v.35, p.23-26, 1995.

KEMPER , W.D., CHEPIL, W.S. Size distribuition of agregates. In: BLACK C. A. Methods of soil analysis. Part 1. Madison : ASA, 1965. p.495-509. 
KERTZMANN, F.F. Modificações na estrutura e no comportamento de um Latossolo Roxo provocados pela compactação. São Paulo, SP, 1996. 153p. Tese (Doutorado em Geografia Física) - Faculdade de Filosofia, Letras e Ciências Humanas, Universidade de São Paulo, 1996.

KLEIN, V.A. Propriedades físico-hídrico-mecânicas de um Latossolo Roxo, sob diferentes sistemas de uso e manejo. Piracicaba, SP, 1998. 130p. Tese (Doutorado em Agronomia/Solos e Nutrição de Plantas) - ESALQ, Universidade de São Paulo, 1998.

LETEY, J. Relationship between soil physical properties and crop productions. Advances in Soil Science, New York, v.1, p.277-294, 1985.

MEROTTO JR, A., MUNDSTOCK, C.M. Wheat root growth as affected by soil strength. Revista Brasileira de Ciência do Solo, Viçosa, v.23, p.197-202, 1999.

NESMITH, D.S. Soil compaction in double cropped wheat and soybean on Ultissol. Soil Science Society of America Journal, Madison, v.51, p.183-186, 1987.

PABIN, J., LIPIEC, J., LODEK, S., et al. Critical soil bulk density and strength for pea seedling root growth as related to other soil factors. Soil \& Tillage Research, Amsterdam, v.46, p.203-208, 1998

RUSANOV, V.A. Effects of wheel and track traffic on the soil and crop growth and yield. Soil \& Tillage Research, Amsterdam, v.19, p.131-143, 1991.

SALIRE, E.V., HAMMEN, J.E., HARDCASTLE, J.H Compression of intact subsoils under short-duration loading. Soil \& Tillage Research, Amsterdam, v.31, p.235-248, 1994.

SEGANFREDO, M.L., ELTZ, F.L.F., BRUM, A.C.R. Perdas de solo, água e nutrientes por erosão em sistemas de culturas em plantio direto. Revista Brasileira de Ciência do Solo, Viçosa, v.21, p.287-291, 1997.

SILVA, V.R. Compressibilidade de um Podzólico e um Latossolo em função do estado inicial de compactação e saturação em água. Santa Maria, RS, 1999. 116p. Dissertação
(Mestrado em Agronomia/Biodinâmica de Solos) - Programa de Pós-graduação em Agronomia, Universidade Federal de Santa Maria, 1999.

SOANE, B.D., OUWERKERK, C. van. Soil compaction problems in world agriculture. In: SOANE, B.D., OUWERKERK, C. van, (eds). Soil compaction in crop production. Netherlands : Elsevier, 1994. p.1-21.

SOWERS, C.F. Consistency. In: BLACK C.A. Methods of soil analysis. Part 1. Madison : ASA, 1965. p.391-399.

THOMPSON, P.J., JANSEN, I.J., HOOKS, C.L. Penetrometer resistance and bulk density as parameters for predicing root system performance in mine soils. Soil Science Society of America Journal, Madison, v.51, p.1288-1293, 1987.

TAYLOR, H.M., ROBERTSON, G.M., PARKER, J.J. Soil strength root penetration relations for medium to coarse textured soil materials. Soil Science, New York, v.102, p.18$22,1966$.

TORMENA, C.A., SILVA, A.P., LIBARDI, P.L. Caracterização do intervalo hídrico ótimo de um Latossolo Roxo sob plantio direto. Revista Brasileira de Ciência do Solo, Viçosa, v.22, p.573-581, 1998.

VEPRASKAS, M.J., MINER, G.S. Effects of subsoiling and mechanical impedance on tobacco root-growth. Soil \& Tillage Research, Amsterdam, v.50, p.423-427, 1986

VOORHEES, W.B. Relative effectiveness of tillage and natural forces in alleviating wheel-induced soil compaction. Soil Science Society of America Journal, Madison, v.47, p.129133, 1983.

VOORHEES, W.B., NELSON, W.W., RANDALL, G.W. Extent and persistence of subsoil compaction caused by heavy axle loads. Soil Science Society of America Journal, Madison, v.50, p.428-433, 1986

VOORHEES, W.B., SENST, C.G., NELSON, W.W Compaction and soil structure modification by wheel traffic in the Northern Corn Belt. Soil Science Society of America Journal, Madison, v.42, p.344-349, 1978.

Ciência Rural, v. 30, n. 5, 2000. 